\title{
RHEUMATOID PNEUMOCONIOSIS IN A FOUNDRY WORKER
}

\author{
BY \\ A. CAPLAN, E. D. H. COWEN, AND J. GOUGH \\ From the Pneumoconiosis Medical Panel, Cardiff, the Lister Hospital, Hitchin, Herts, and the \\ Welsh National School of Medicine, Cardiff
}

There is now ample evidence that a particular type of appearance in chest radiographs of workers exposed to a variety of dust hazards is closely associated with the presence of rheumatoid disease. The original cases in coal workers were observed in Wales (Caplan, 1953 ; Miall, Caplan, Cochrane, Kilpatrick, and Oldham, 1953), but similar examples have been seen in coal workers in other parts of Great Britain and in other European countries (Christiaens, Balgairies, Foubert, Aupetit, and Grailles, 1954 ; Petry, 1954 ; van Mechelen, 1954 ; Dechoux and Ruyssen, 1956 ; von Sepke, 1957).

Up to the present, examples of this syndrome in workers exposed to dusts other than coal have been published only outside Britain. Colinet (1950 and 1953) in France described it in relation to a silica hazard. From Belgium, Clerens (1953) described two cases in female workers from the same factory exposed to a pure silica hazard. From Holland, van der Meer (1954) reported one case in a man who had worked as a diamond and metal polisher and also as a sand blaster. Martin and Fallet (1953) considered that they had seen one instance in a miner exposed to a pure silica risk in Switzerland.

Cases of the rheumatoid pneumoconiosis syndrome have been observed in Great Britain in workers exposed to a variety of dusts other than coal, as in potteries, sand blasting, brass and iron foundries (Caplan, unpublished). In this number of this Journal, cases are reported in a boilerscaler (Campbell, 1958) and an asbestos worker (Rickards and Barrett, 1958). These, and the following account of a case in a foundry worker, emphasize the prevalence of the syndrome in workers exposed to a wide variety of dusts.

Briefly, the characteristic radiological features are multiple, well-defined round opacities 0.5 to $5 \mathrm{~cm}$. in diameter distributed throughout both lung fields. In many cases the background of simple pneumoconiosis is slight or may be absent and the opacities often appear with a suddenness that is not usually observed in the development of ordinary progressive massive fibrosis (P.M.F.). The opacities may appear before, coincident with, or after the onset of arthritis, and there is no apparent relationship between the severity of arthritis and the extent and type of the radiological changes. In some cases the opacities increase in size and number and crops of fresh lesions may appear at intervals of a few months, whilst in others only a few round opacities are localized to one or more areas of the lung fields and remain stationary. It is not uncommon for the lesions to cavitate and thereby disappear or fibrose. Calcification is fairly common and in many instances the lesions ultimately become incorporated in P.M.F. More cases may be recognized if it is realized that in the majority there is a mixed radiological picture of round opacities, P.M.F., and opacities indistinguishable from tuberculous lesions.

A detailed pathological study of the syndrome has been made by Gough, Rivers, and Seal (1955). They described the lung lesions in 16 coal workers, from material obtained at necropsy and biopsy, as having a characteristic appearance and distinguishable from P.M.F. and the classical silicotic nodule. Macroscopically the lesions show a characteristic concentric arrangement of lighter and darker layers. The pale areas are grey in some instances and yellow in others. Liquefaction tends to occur in the pale areas leaving clefts. In some cases the nodules are densely calcified.

The histological criteria upon which diagnosis should be made are a central area of necrotic collagen, outside which is a zone of active inflammation consisting of a cellular infiltration of macrophages and frequently also of polymorphonuclear leucocytes. In this zone collagen is being destroyed. In haematoxylin-and-eosinstained sections the intense blue staining of the inflammatory zone contrasts with the pink of the central necrotic collagen. Some of the macrophages in the inflammatory zone contain dust. When these macrophages die and disintegrate the dust is deposited and this accounts for the dark 
concentric rings seen in the nodules. The inflammatory zone may involve the whole or only part of the circumference of a nodule. Multinucleated giant cells are present in some instances, and these lie in a zone of fibroblasts outside the zone of inflammatory cells. The fibroblasts are orientated in a palisade manner. Outside the palisade is a zone of collagen arranged circumferentially and not necrotic. Endarteritis is present in vessels at the periphery of the nodules, and in the lumen of the vessels there are more lymphocytes and plasma cells than seen in the endarteritis usually present in pneumoconiosis.

\section{CASE Report}

A man aged 48 was first seen in November, 1952, complaining of pains in both shoulders and inability to straighten his right elbow for 10 weeks. There had been a previous similar attack in March, 1952. Cough had also been present for the past seven years. The only past illnesses of significance were gonorrhoea and syphilis, adequately treated, 15 years previously. There was no family history of rheumatoid arthritis.

His job at that time was that of crane driver in an iron foundry, but he had worked there since 1934, for two years as a sand-blasting labourer, for about three years sand-blasting castings, and for six years as a steel trimmer and fettler. In 1945 he became a slinger on the crane, and finally driver.

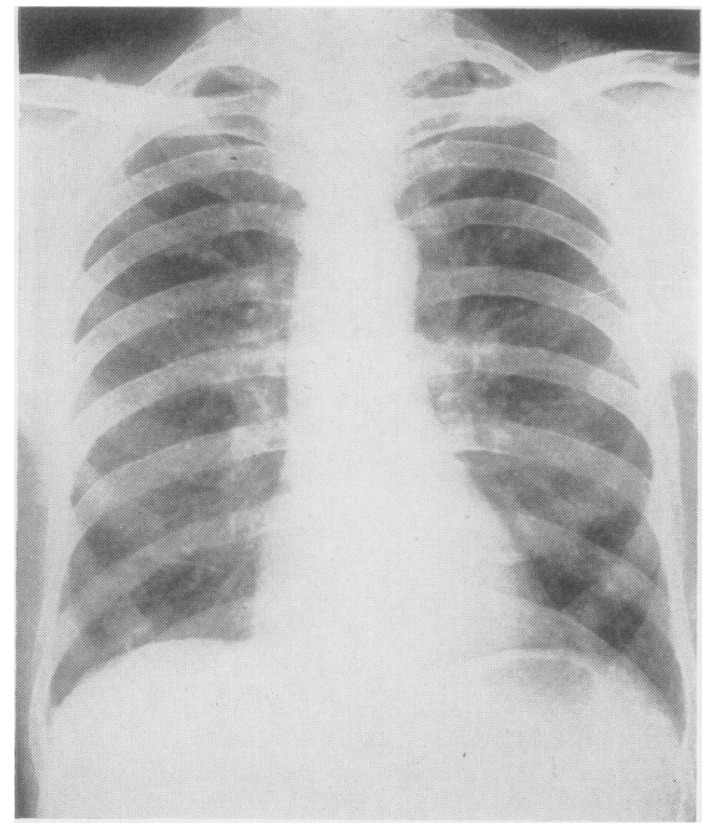

FIG. 1.-7.11.52. In addition to Category 1 pneumoconiosis there is a round opacity in the right upper zone and a group of irregular opacities in both lower zones.



FIG. 2.-29.6.54. A number of round and irregular opacities are present in the right upper and lower zones, and left upper, mid and lower zones.

He was a small, rather thin $(112 \mathrm{lb} ., 55 \mathrm{~kg}$.$) , deaf$ man. There was typical rheumatoid arthritis of both shoulders, right elbow, both knees, and finger joints. Radiographs of the hands confirmed the diagnosis. The chest film showed, in addition to a Category 1 pneumoconiosis, a round opacity about $1 \mathrm{~cm}$. in diameter in the right upper zone and a group of small irregular opacities in both lower zones (Fig. 1).

$\mathrm{He}$ was re-examined at regular intervals and was admitted to hospital on four occasions, twice (1952 and 1953) for treatment of arthritis and twice (1954 and 1957) for duodenal ulcer.

The serum Wassermann reaction and Kahn and G.C.F. tests were negative. The sputum was examined for tubercle bacilli on many occasions and was invariably negative on smear and culture. Mantoux tests with $1 / 1,000$ old tuberculin gave the following results : 8.8 .54 , positive; 19.8 .54 , strongly positive. The Rose-Waaler test was negative at a titre of 1 in 8 .

During the five years under observation he $\mathcal{O}$ remained at work most of the time as a crane driver; N he was rather short of breath with a cough productive $\mathrm{N}$ of about an eggcupful of purulent sputum each day. $\omega$ Moderate clubbing of the fingers slowly developed. The joints most severely affected were the hands and 0 shoulders. The E.S.R. was between 80 and $100 \mathrm{~mm}$. $\frac{\Phi}{}$ in one hour. The weight decreased to $110 \mathrm{lb}$. $(50 \mathrm{~kg}$.). $\stackrel{?}{+}$ The chest films showed fairly rapid development of $\tau$ round opacities throughout both lungs with ultimate coalescence in some areas. The presence of a few isolated opacities in the 1952 film contrasts greatly 


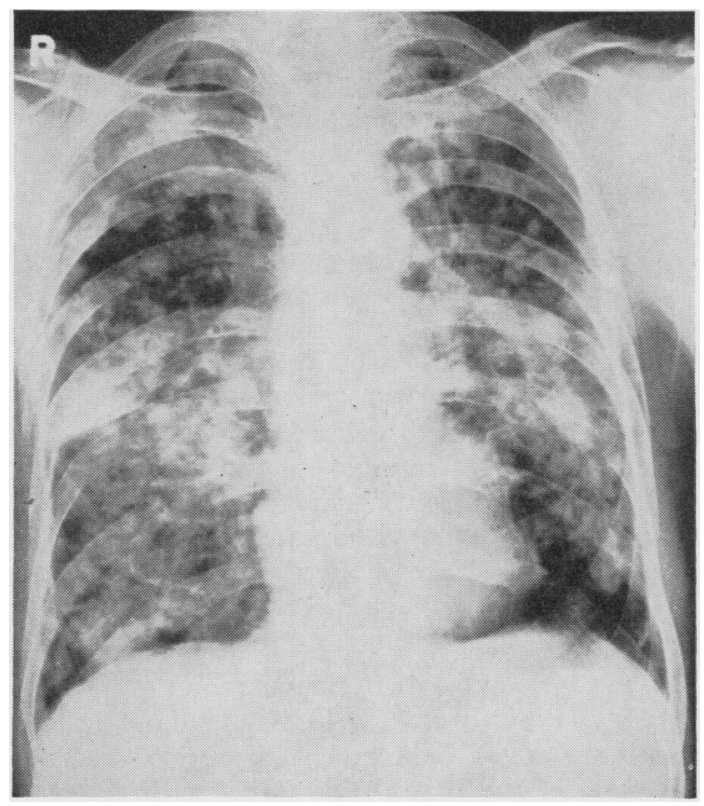

FIG. 3.-15.4.57. The round opacities are now widespread throughout all zones of both lung fields and there is coalescence of opacities in both upper, mid, and lower zones.

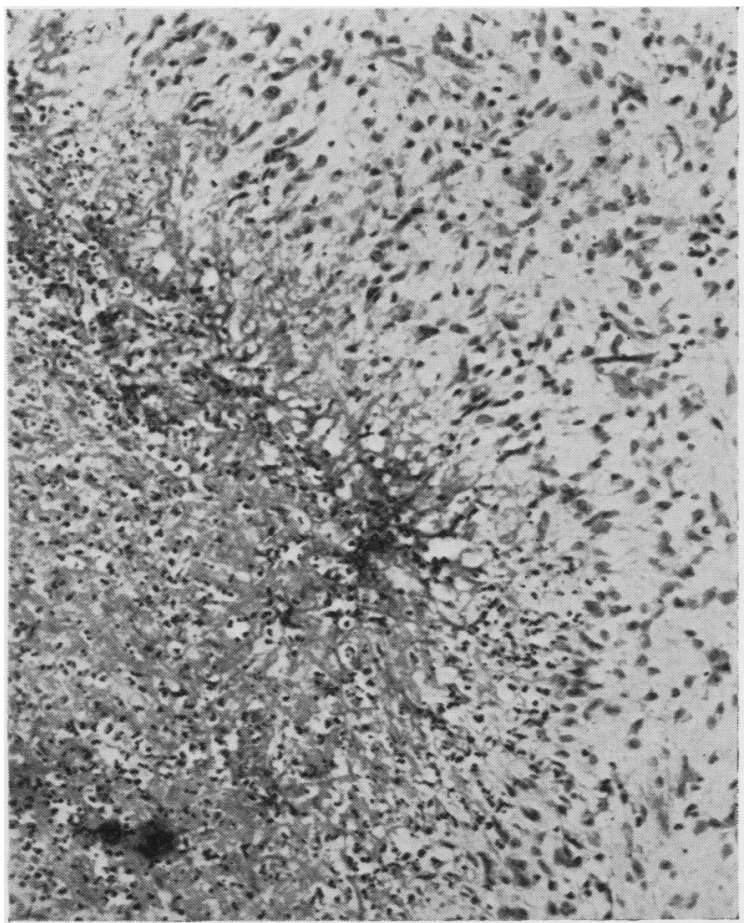

FIG. 5. $-\times 170$. Subcutaneous nodule from elbow. Central necrosis. Outer palisade of cells.

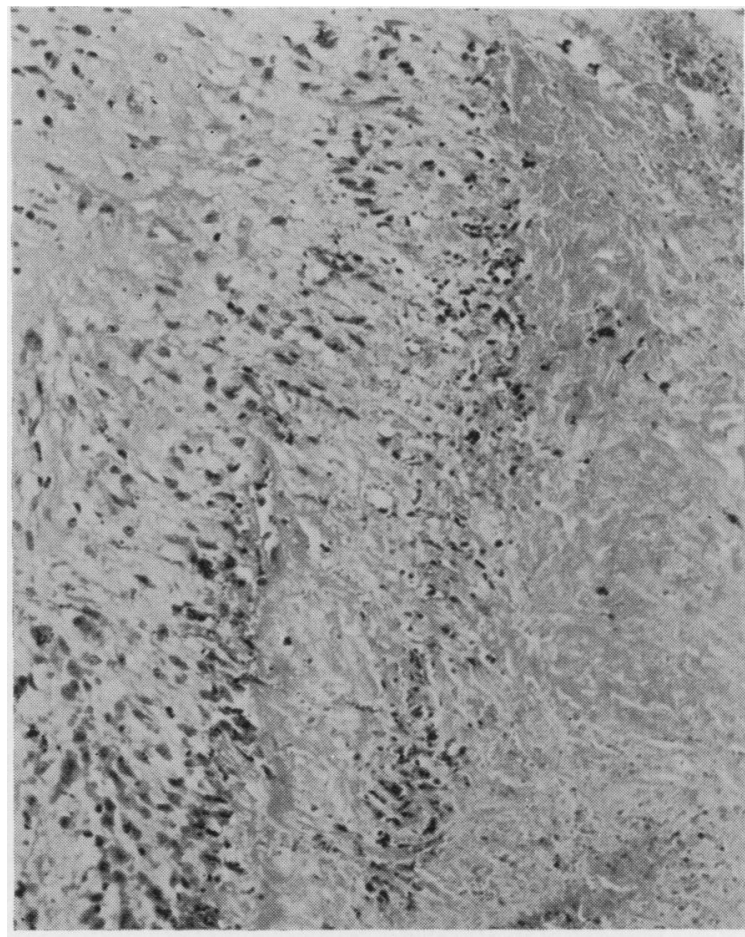

FIG. 4. $-\times$ 170. Lung nodule. Central necrosis. Outer palisade of cells.

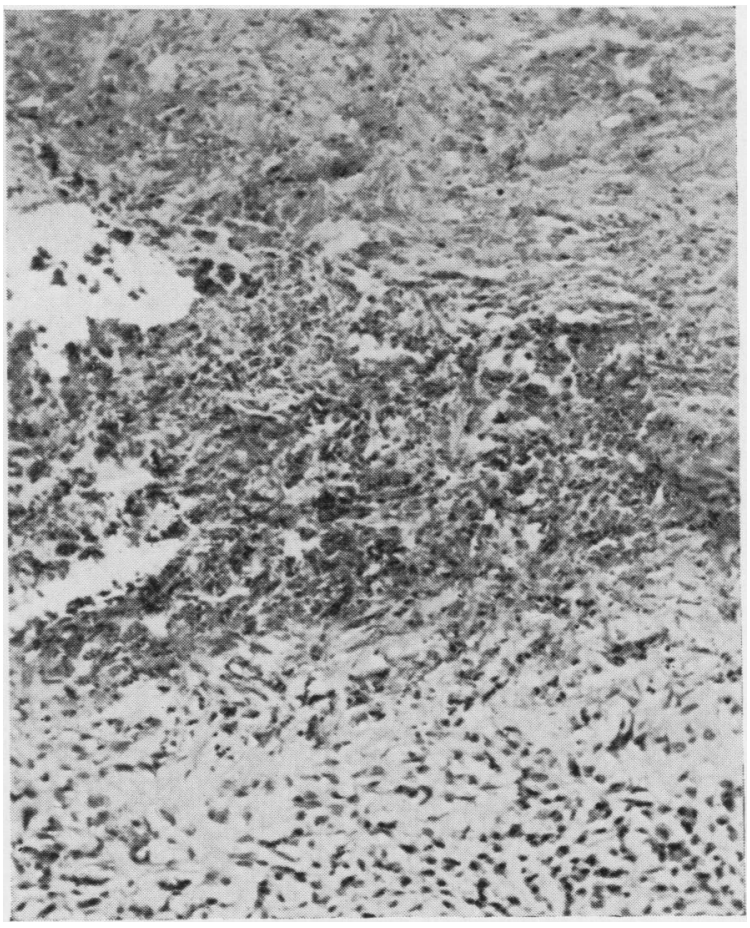

FIG.6.- $\times$ 170. Lung nodule. An area liquefying to form a cleft. 
with the widespread and numerous opacities in the 1957 film (Fig. 3). Fig. 2 shows the appearance at an intermediate date.

In May, 1957, because of the difficult differential diagnosis of the lung lesions, a thoracotomy was advised and a biopsy of the right lower lobe was performed by Mr. G. C. W. James. At operation it was observed that the pleural space was obliterated by dense vascular adhesions which were fairly easily separated by sharp dissection. The whole of the lung, especially the right upper lobe and right lower lobe, contained solid hard nodules which, because of coalescence in places, made measurement difficult. Some plaques with serpiginous blackened edges were visible on the pleura, the plaques being rather yellowish in colour. The hardness of the nodules was such as to suggest calcification.

The biopsy tissue contained a nodule $4 \mathrm{~mm}$. in diameter. It showed the characteristics of rheumatoid pneumoconiosis described above except that there was no endarteritis. Part of the nodule is illustrated in Fig. 4. There is palisading of cells outside a necrotic zone. The nuclear remnants and dust of a former cellular zone are still visible. The specimen, however, also contained a focus of simple pneumoconiosis unaffected by the rheumatoid change. For comparison with Fig. 4 is a corresponding zone from a subcutaneous nodule of the elbow of the same man (Fig. 5). A characteristic difference between lung and subcutaneous nodules is the somewhat greater tendency for the lung ones to break down to form clefts or cavities (Fig. 6).

\section{Discussion}

In retrospect, examination of the chest radiographs and the biopsy material shows this case to be a typical example of the rheumatoid pneumoconiosis syndrome. A few round opacities in the chest films were present some eight months after the onset of typical clinical rheumatoid arthritis. Over a period of five years there appeared crops of fresh lesions and the original opacities increased in size with ultimate coalescence of the opacities in the upper, middle and lower zones. The biopsy material showed the characteristic histological features of rheumatoid pneumoconiosis.

The lung lesions are identical in appearance wit'? those seen in coal workers; this suggests that a necessary factor in the causation of the lesion is the presence of collagen, formed either as a result of the reaction to dust or to dust and tuberculosis. It is not yet known why pneumoconiotic lesions are subject to rheumatoid change. The collagen necrosis, which is a predominant feature of the lesion, may be either the cause or the result of the abnormal response.

It has come to the notice of one of us (A.C.) that a diagnostic exploratory thoracotomy has been performed in other patients suffering from rheumatoid arthritis (albeit mild and perhaps insignificant) in order to elucidate the pathology of round opacities in chest radiographs. It is hoped that the publication of this case may lead to the rheumatoid pneumoconiosis syndrome being included in the differential diagnosis of multiple round opacities in chest radiographs and thereby lessen the necessity for a thoracotomy.

\section{SUMMARY}

A case of rheumatoid pneumoconiosis in a foundry worker is presented. The radiological appearances and the histological changes in lung biopsy material are described. The appearances are identical with those seen in coal workers.

Acknowledgments are due to Mr. G. C. W. James, consultant thoracic surgeon, and Dr. Misch, of the Pathological Laboratory of the Lister Hospital, Hitchin, for their generous help ; and to Mr. Harris of the Pneumoconiosis Research Unit, for prints of the chest radiographs. Photomicrographs are by Mr. J. P. Napper.

REFERENCES
Campbell, J. (1958). Thorax, 13, 177.
Caplan, A. (1953). Ibid., 8, 29.
Christiaens, L., Balgairies, E., Foubert, P., Aupetit, J., and Grailles,
M. (1954). Rev. Rhum., 21, 1.
Clerens, J. (1953). Arch. belges Méd. soc., 11, 336.
Colinet, E. (1950). Acta physiother. rheum. belg., 5, 185.
(1953). Ibid., 8, 37.
Dechoux, J., and Ruyssen, L. (1956). Strasbourg. méd., 7, 399.
Gough, J., Rivers, D., and Seal, R. M. E. (1955). Thorax, 10, 9.
Martin, E., and Fallet, G. H. (1953). Schweiz. med. Wschr., 83, 776.
Mechelen, M. V. van (1954). Arch. Mal. prof., 15, 525.
Meer, C. van der (1954). Ned. Geneesk., 98, 3539.
Miall, W. E., Caplan, A., Cochrane, A. L., Kilpatrick, G. S., and
Oldham, P. D. (1953). Brit. med. J., 2, 1231.
Petry, H. (1954). Arch. Gewerbepath. Gewerbehyg., 13, 221.
Rickards, A. G., and Barrett, G. M. (1958). Thorax, 13, 185.
Sepke, G. von (1957). Tuberkulosearzt, 11, 154.

